DOI: $10.1515 / \mathrm{rrlm}-2017-0029$

\title{
The impact of immunological and biomolecular investigations on the outcome of children with acute lymphoblastic leukemia - experience of III ${ }^{\text {rd }}$ Paediatric Clinic Timisoara
}

\author{
Cristian Jinca ${ }^{1}$, Carmen Angela Maria Petrescu ${ }^{1}$, Estera Boeriu ${ }^{1}$, Andrada \\ Oprisoni ${ }^{1}$, Loredana Balint-Gib ${ }^{2}$, Mihaela Baica ${ }^{2}$, Cristina Popa ${ }^{1}$, Nicoleta

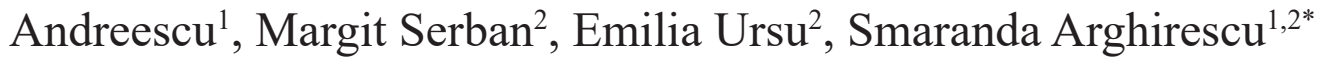 \\ 1. University of Medicine and Pharmacy "V. Babes", Timisoara, Romania \\ 2. Emergency Children's Hospital "L.Turcanu”, Timisoara, Romania
}

\begin{abstract}
Introduction. The unsatisfactory results of the survival in patients with acute lymphoblastic leukemia (ALL) until 2000 in our center have led us to improve the approach of diagnosis and therapy. Since 2003 in all patients the following have been performed: flow cytometry, conventional genetic diagnosis, FISH (fluorescent in situ hybridization), and molecular biology. Objectives. Our aims were to identify solutions to increase patients'survival. Patients and method. It is a single-center, retrospective study of 136 patients with ALL treated at 3rd Pediatric Clinic of Timisoara, over a period of 10 years (2003-2012), where survival was assessed. Results. Morphologically, $86 \%$ of the patients were L1 type, 13\% L2 type and 1\% L3 type. Flow citometry revealed that $68 \%$ were ALL with $B$ precursors, and 19\% with T immunophenotype. Acute leukemia with mixed phenotype (biphenotypic) was identified in $2.3 \%$ of patients and $10.7 \%$ of the forms were acute leukemia with myeloid markers. In $27.7 \%$ of patients, mutations were detected by the RT-PCR method, the most commonly identified was TEL-AML1 (ETV6-RUNX1) accounting for $12.7 \%$ of the cases. Relapse-free survival at 5 years for the entire group was $59 \%$, and for the group treated between 2008 and 2012 it was 72\%. Conclusion. Our analysis confirms the decisive value of laboratory investigations for the prognosis and improvement of supportive therapy.
\end{abstract}

Keywords: leukemia, immunophenotyping, fusion genes, children

Received: 29 $9^{\text {th }}$ May 2017; Accepted: 18 ${ }^{\text {th }}$ August 2017; Published: 25 th August 2017

*Corresponding author: Smaranda Arghirescu, Emergency Children’s Hospital “ L.Turcanu”, Timisoara, Romania. E-mail: sarghirescu@yahoo.com 


\section{Introduction}

Acute leukemias represent a clonal expansion and arrest at a specific stage of differentiation of normal myeloid or lymphoid hematopoiesis. Acute lymphoblastic leukemia (ALL) is defined as a heterogeneous group of malignancies, characterized by the proliferation of a malignant clone that remains in a certain stage of development (1). It is the most common form of cancer in children, being responsible for about $30 \%$ of the childhood malignancies and $75 \%$ of all leukemias (2). ALL is a multifactorial disease due to interaction of endogenous and exogenous factors, as well as genetic predisposition.

ALL is associated with several chromosomal anomalies, varying from aneuploidies (hyperdiploidy, hipodiploidy) to different types of chromosomal rearrangements (translocation: $\mathrm{t}(12 ; 21)(\mathrm{p} 13 ; \mathrm{q} 22), \quad \mathrm{t}(1 ; 19)(\mathrm{q} 23 ; \mathrm{p} 13), \quad \mathrm{t}(9 ; 22)$ (q34;q11), MLL and MYC rearrangement and dysregulation of several genes: TAL1, P53, $T L X 1, T L X 3$ and $L Y L 1$ (1,3). Identification of genetic patterns for each patient is important as they impact the prognosis and allow patients' stratification for treatment. It is known that the translocation $\mathrm{t}(12 ; 21)(\mathrm{p} 13 ; \mathrm{q} 22)$ and hyperdiploid state represent an indicator for a good outcome while hipodiploidy and MLL aberrations are associated with a poor prognosis (4-6).

For a correct and comprehensive diagnosis, there is a need to assess, besides the cell morphology and cytochemistry, immunophenotyping, cytogenetic, and molecular investigation for each patient. As the cytogenetic and molecular profile became indispensable for patients' stratification and identification of minimal residual disease, the genetic investigations are mandatory. (7) An important step forward was registered when polymerase chain reaction (PCR) was introduced for the assessment of minimal residual disease (MRD), for personalization of therapeutic approaches. There are several methods used for MRD assessment: immunophenotyping using flow cytometry, PCR analysis of fusion products resulting from chromosomal translocations, and RQ-PCR to determine the remission status. $(8-11)$

\section{Patients and methods}

\section{Patients}

The current study is a retrospective, descriptive study, conducted at the Emergency Children's Hospital "Louis Turcanu" Timisoara that included patients diagnosed with ALL and treated between 2003 and 2012. The study includes 167 consecutive children, with different subtypes of ALL. Of these, 136 met the inclusion/ exclusion criteria.

\section{Diagnosis of $A L L$}

The following investigations were performed for all patients on blood and bone marrow: white blood cell differential counts, light microscopy evaluation, immunophenotyping using the multicolor flow cytometer and genetic characterizations. Morphological classification was performed according to the FAB type. For Immunophenotyping, a panel of commercially available antibodies was used as previously described. BFM (Berlin-Frankfurt-Munster) criteria were used for interpretation of the results, the thresholds being set to: $10 \%$ for intracellular markers and 20\% for surface antigens. (12)

Conventional cytogenetic analysis of bone marrow was done by following the standard protocol, after 24 hour of unstimulated culture. For chromosome evaluation, GTG banding using trypsin for digestion and Giemsa staining was done. At least 30 metaphases were counted and karyotypes were reviewed in accordance with the ISCN (International System for Cytogenetic Nomenclature) regulations. Aneuploidies were considered only the cases where a minimum of two metaphases presented the same additional 
chromosome and cases where three metaphases with the same chromosome loss could be found. For structural chromosome abnormality, at least 2 clones with the same aberration were required in order to be considered a structural variant.

For molecular genetic investigations, bone marrow samples were collected in EDTA tubes and used for RNA extraction. RNA samples were stored at $-80^{\circ} \mathrm{C}$ until used for c DNA synthesis. Q-RT-PCR was done according to the optimized protocol previously described (13). We used assays designed to detect: E2A-PBX1, MLLAF4, TEL-AML1, BCR-ABL1, SIL-TAL1.

\section{Treatment}

All our patients were treated in accordance with standard protocols ALL-BFM. Treatment administration was initiated after receiving the informed consent from the parents or tutors of the children. The hospital ethics committee approval was received prior to starting data collection.

\section{Statistical analysis}

Statistical analysis was performed using the IBM ${ }^{\circledR}$ SPSS $®$ Statistics version 20 . Event-free survival (EFS) rates were estimated by the method of Kaplan and Meier, and were compared using the 2-sided log-rank test. A level of statistical significance $p$-value $<0.05$ was considered as significant.

\section{Results}

The cohort included 136 patients, $66.17 \%$ male and $33.83 \%$ female patients, aged between 4 months- 24 years, with a median age of 5 years.

Regarding the French-American-British (FAB) classification of ALL patients based on the morphology allowed stratification of the patients in 3 groups: L1, L2, or L3. 109 patients (86\%) were recorded as L1, 21 patients (14.4\%) were recorded as L2 and one patient's blasts
$(0.6 \%)$ presented L3 morphology. Flow cytometry was used to classify patients based on the immunophenotype: $68 \%$ of the patients presented a B-phenotype, 19\% T-phenotype, and the rest were either mixed-phenotype acute leukemia or biphenotypic acute leukemia (MPAL) in a proportion of $2.3 \%$ or ALL with aberrant myeloid marker expression (My+ALL) in a proportion of $10.7 \%$. Besides the molecular analysis applied within the diagnostic workup, conventional cytogenetic analysis was also performed. Kariotyping was performed in $42.6 \%$ of the children. Hyperdiploidy was identified in $6.7 \%$, whereas hypodiploidy in $3.7 \%$.

In 35 out of 136 patients (25.7\%), gene expression/fusion gene transcripts were detected by RT-PCR. We found $12.7 \%$ of the patients to be positive for TEL-AML1, 3\% had MLL-AF4 fusion gene, $3.3 \%$ were SIL-TAL positive, $3 \%$ patients presented the BCR-ABL1 fusion gene, $3.7 \%$ were E2A-PBX1 fusion gene positive.

All patients were treated according to the BFM protocol, differentiated by risk groups: the standard risk (SR) group included $11.19 \%$ of the patients; the medium risk (MR) group consisted of the majority of the patients $(69.4 \%)$, whereas the high risk (HR) group included $19.4 \%$ of the patients. High risk framing was done using the genetic mutation as the only criterion. Patients treated during the period 2003-2007 did not receive adequate supportive treatment (isolation, antifungal prophylactic treatment, pneumocystis prophylaxis), while the group treated in 20082012 benefited from supportive treatment to replacement cytostatics in the case of allergy to the original product. In addition, the 2009 BFM protocol has as the sole criterion for monitoring the evolution of treatment minimal residual disease performing by flow cytometry and RT-PCR.

10 year-EFS for the entire cohort was $58 \%$ with a mean duration of survival of $6.662 \pm 0.410$ years, $\mathrm{CI}=95 \%$, but when comparing 5-year EFS rates between the patients treated between 2003- 
2007 and those treated in the second period (2008-2012), there was a significant difference: $50.6 \%$ (mean $5.9 \pm 0.534$ years, $\mathrm{CI}=95 \%$ ) vs 72 $\%$ (mean $4.4 \pm 0.289$ years, $\mathrm{CI}=95 \%$ ) respectively $(p=0.032)$ (Figure 1).

When comparing the survival rates between risk groups, we found that patients in the SR and MR group fared better than those in the HR group $(66.7 \%$ and $63.9 \%$ for the SR and MR group compared to $23.8 \%$ in the HR group, $p=.001$ ) (Figure 2).

The survival analysis for each category of patients based on the presence of cytogenetic alterations showed that TEL-AML1 was associated with the best prognosis ( $\mathrm{pEFS}=79,5 \%$ ), even better that the majority of the patients who did not present any detectable gene rearrangement, whereas BCR-ABL1 and SIL-TAL positive patients had a worse prognosis. The results are statistically significant $(\mathrm{p}=.004)$ (Figure 3 ).

Patients presenting B-precursor ALL had a better outcome as compared with the $\mathrm{T}$ phe- notype ALL (62.2\% vs 41.7\%) (Figure 4). Patients with lymphoblasts aberrantly expressing myeloid markers fared better that those with a T phenotype even though the survival curve included the $2.3 \%$ of patients with true MPAL.

\section{Discussions}

Generally accepted prognostic factors for ALL are: age, leukocyte count, immunophenotype, and cytogenetic anomalies. (14-18) The most valuable markers, for their predictive value, are the immunological and biomolecular features of the leukemic cells. (19-21)

The identification of fusion genes was used for risk stratification and as prognostic markers. Genetic anomalies were found in $25.7 \%$ of the patients enrolled in this study. The frequency of the genetic modification in the present study is lower than reported previously. Fusion genes were identified in 34 patients. The risk stratification within the BFM protocols requires the iden-

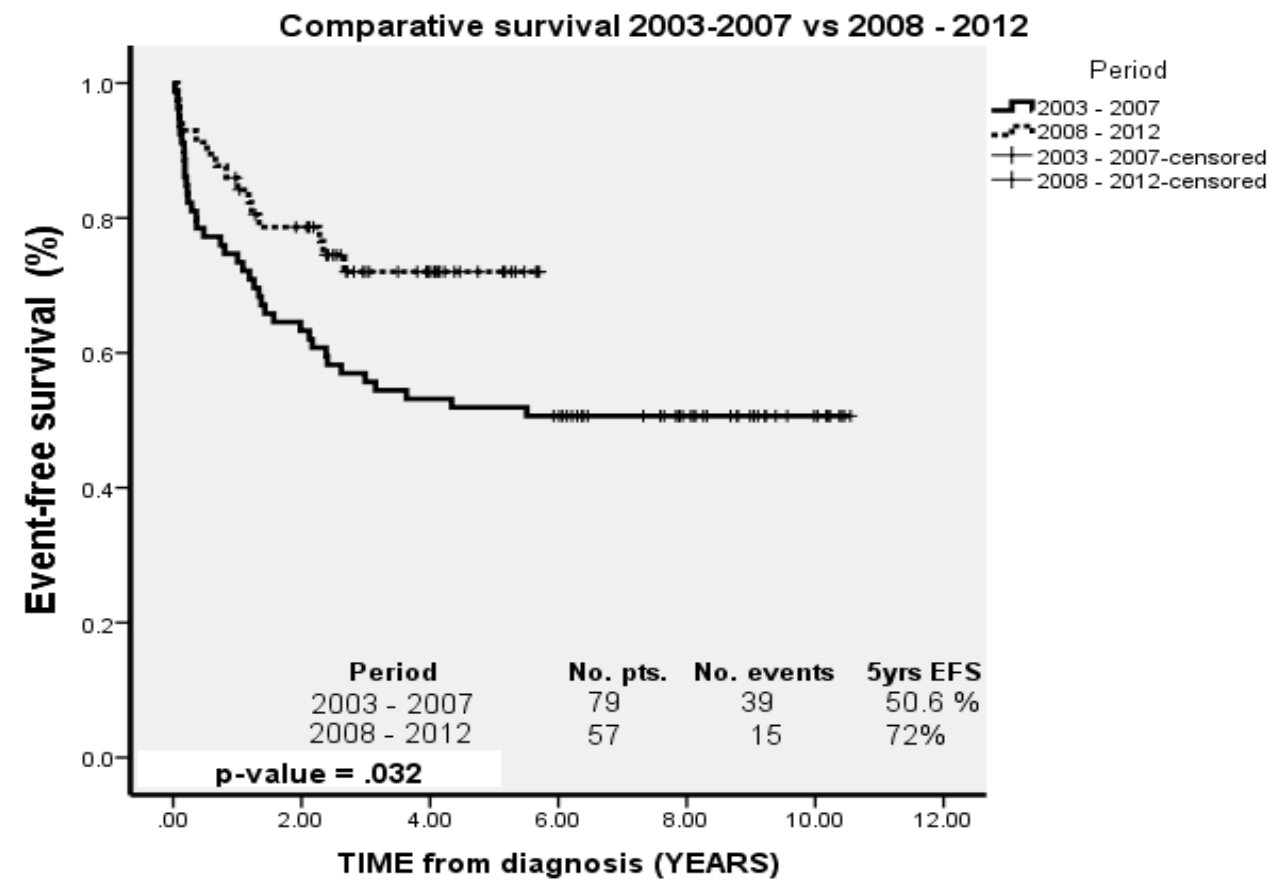

Figure 1. Log-rank test to compare event-free survival for patients treated before 2008 and after 2008 


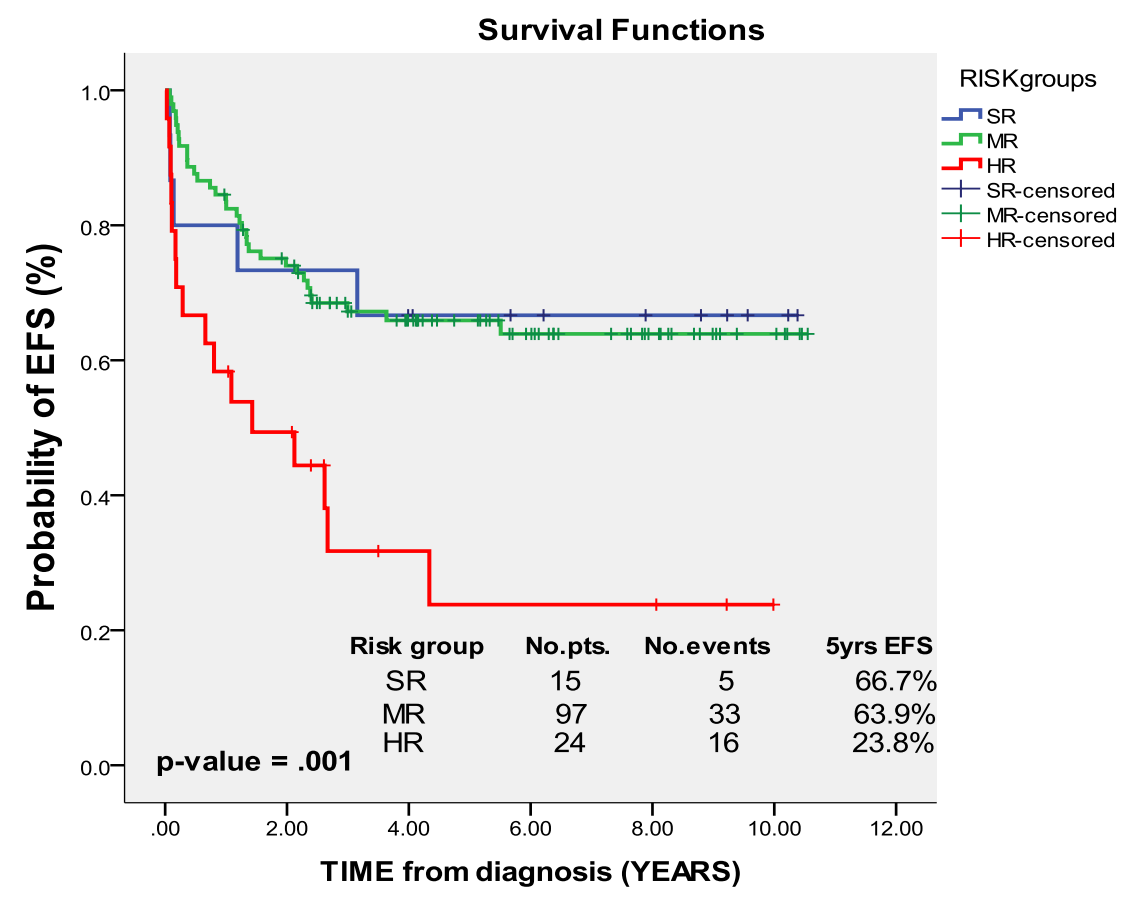

Figure 2. Kaplan-Meier estimate of event-free survival for the identified risk groups

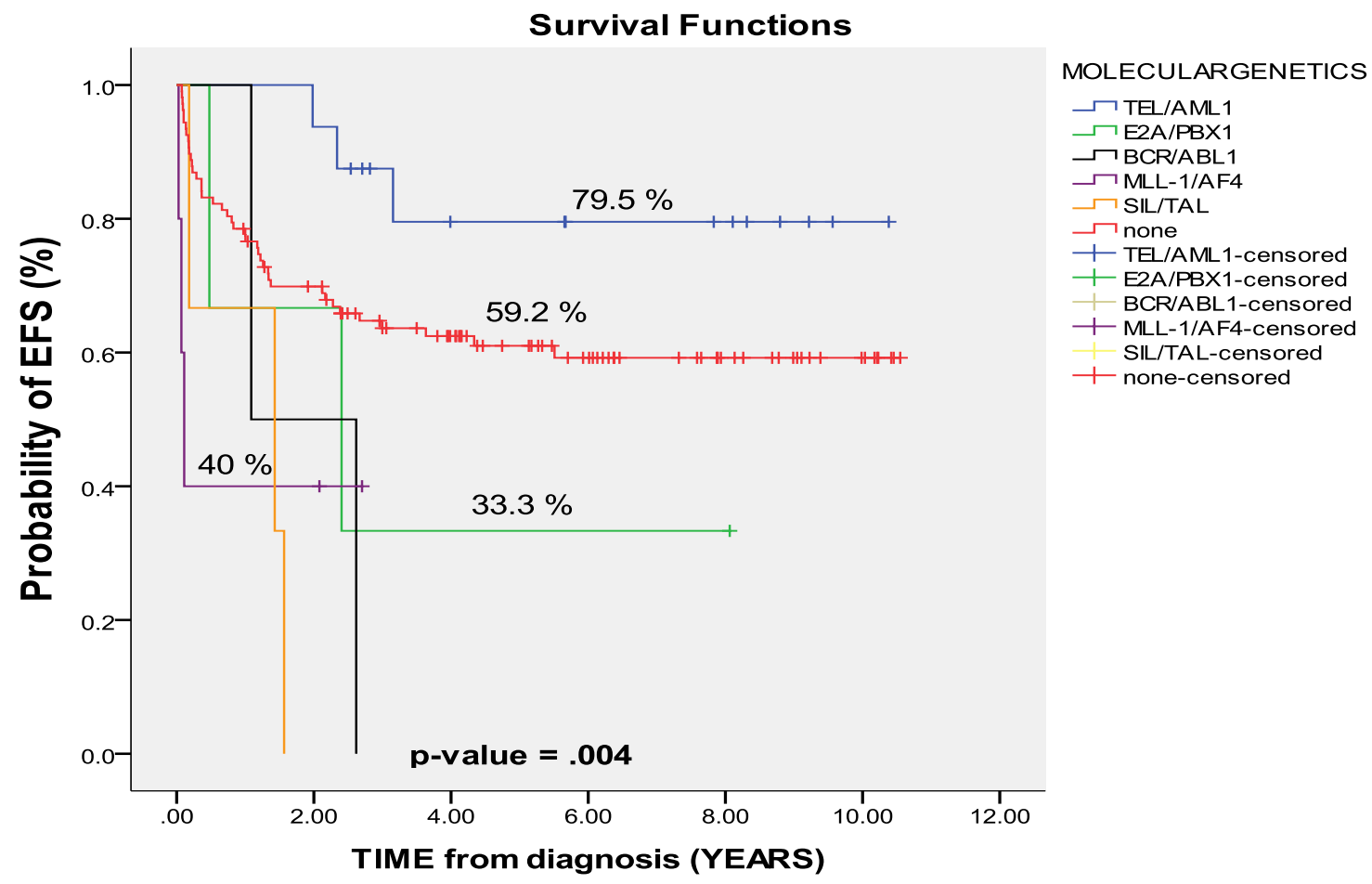

Figure 3. Kaplan-Meier estimate of event-free survival based on the gene rearrangements identified 


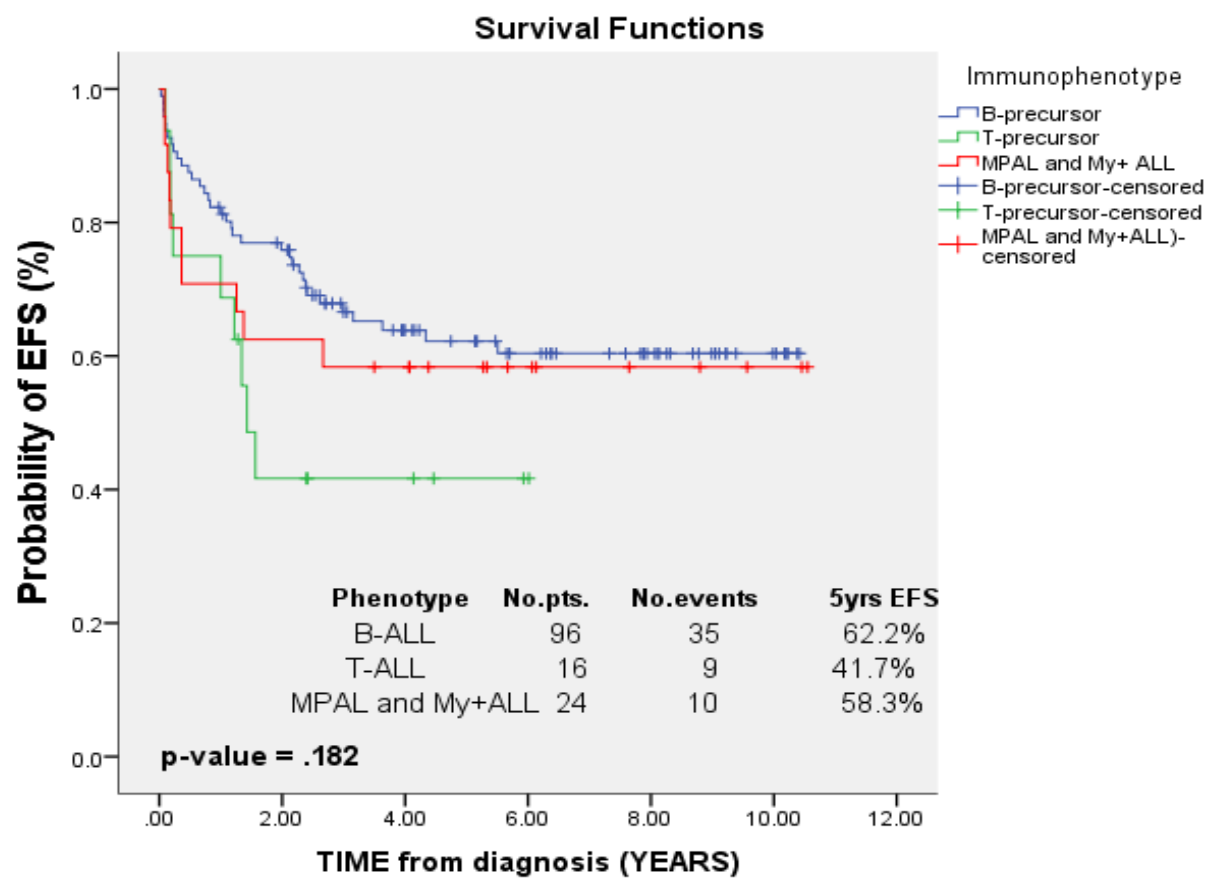

Figure 4. Kaplan-Meier estimate of event-free survival based on immunophenotype

tification of the fusion genes associated with a poor prognosis: BCR-ABL1 and MLL-AF4. Minor BCR-ABL1 as a result of the translocation $t$ $(9 ; 22)$ and the MLL-AF4 fusion gene as a result of $t(4 ; 11)$ had the same incidence $(3 \%)$, both with a slightly higher incidence than reported in literature. TEL-AML1 was the most frequent fusion gene identified. This is in accordance with previous reports showing that TEL-AML1 is the most common anomaly (incidence around 25\%) in ALL patients in Western Europe and the United States (US) $(22,23)$. The incidence in the current study was lower than reported in the West of Europe and the US, but comparable with the incidence reported in the Far East (12,7\% in the current study and $13.4 \%$ in the Far East) (22). As previously reported, TEL-AML1 was found in younger children, 15 children were under the age of 7 , one patient was 12 years old, and another one was 13 years old (23).

MLL-AF4 was found in 4 patients. This gene fusion is more frequent in neonatal ALL and has a lower frequency in older patients being associated with a poor prognosis in both age groups (23).

BCR-ABL1 fusion gene is a hallmark for chronic myeloid leukemia (CML), but about 5\% of pediatric ALL and $20-50 \%$ of adult ALL cases associate this genetic anomaly $(24,25)$. For ALL patients, the minor BCR-ABL1 fusion gene represents an indicator of poor prognosis (26). In the current study, patients exhibiting the BCRABL fusion gene had an early relapse of the disease. E2A-PBX1 fusion gene is more common in non-Caucasians, being reported in about $5-6 \%$ of childhood ALL $(27,28)$. For patients exhibiting the E2A-PBX1 translocation, a poor prognosis is foreseen and therefore a more intensive chemotherapy management is recommended (29). Patients exhibiting the E2A-PBX1 gene fusion, presented late relapses, after more than 3 years after the diagnosis. Different studies showed controversial results with respect to the prognosis of the patients SIL-TAL rearrangements 
(30-32). In the present study, early relapses after diagnosis were registered for the patients having SIL-TAL rearrangements: one patient presented relapse in less than one year from the diagnosis, the other two patients relapsed between one year and two years after the moment of diagnosis.

As far as the impact of immunophenotype is concerned, patients with precursor B cell leukemia had a better outcome as compared with those presenting $\mathrm{T}$ phenotype. Patients with My+ALL seem to have a similar outcome with those with B-precursor ALL. The survival curve includes patients with true MPAL. It has been shown that true MPAL patients have a poor prognosis, especially in adults, and patients positive for the minor BCR-ABL1 fusion gene (33). None of our patients with MPAL expressed BCR-ABL1.

The 10 year-EFS for the whole cohort was inferior to that reported in literature but, the comparative analysis between the outcome before and after 2008 showed a significant improvement, mainly due to a better diagnostic approach, but also due to the use of alternative Asparaginase preparations in cases with L-Asparaginase allergy and to improved supportive care. In addition to this, access to unrelated hematopoietic stem cell donors has contributed in a positive way to the salvation of patients with a poorer prognosis.

\section{Conclusions}

The current study presents a single center experience regarding the management of children with ALL, and evaluates the factors that may impact the prognosis of the patients. The frequency of gene fusion transcripts in the current study was lower as compared with other reports from the literature. TEL-AML1 was the most frequent gene fusion observed in the present study, but had a lower incidence than in the Western European population. By using immunophenotyping and detection of fusion genes, stratification of the patients is possible and allows a better therapeutic decision making and evaluation of treatment response. Minimal residual disease (MRD)-based risk stratification of patients was introduced in the current protocols for managing children with ALL, and is considered the gold standard for risk assignment.

Our analysis confirms the decisive value of the immunological and cytogenetic investigations in the diagnosis and the treatment stratification of patients with ALL. It can also reveal some particular aspects. The extension of this analysis towards a multicentric approach involving a much larger number of patients would be appropriate for a more rigorous correlation between the biological markers and the outcome of our patients.

\section{References}

1. Inaba H, Greaves M, Mullighan CG. Acute lymphoblastic leukaemia. The Lancet. 2013 Jun;381(9881):194355. DOI: 10.1016/S0140-6736(12)62187-4

2. Bartram CR, Schrauder A, Köhler R, Schrappe M. Acute lymphoblastic leukemia in children: treatment planning via minimal residual disease assessment. Dtsch Arzteblatt Int. 2012 Oct;109(40):652-8.

3. Harrison CJ. Cytogenetics of paediatric and adolescent acute lymphoblastic leukaemia. $\mathrm{Br} \mathrm{J}$ Haematol. 2009 Jan;144(2):147-56. DOI: 10.1111/j.13652141.2008.07417.x

4. Pui C-H, Robison LL, Look AT. Acute lymphoblastic leukaemia. Lancet Lond Engl. 2008 Mar 22;371(9617):1030-43. DOI: $10.1016 / \mathrm{S} 0140-$ 6736(08)60457-2

5. Mullighan CG, Collins-Underwood JR, Phillips LAA, Loudin MG, Liu W, Zhang J, et al. Rearrangement of CRLF2 in B-progenitor and Down syndrome associated acute lymphoblastic leukemia. Nat Genet. 2009 Nov;41(11):1243-6. DOI: 10.1038/ng.469

6. Kamariah Ibrahim, Siti Sarah Daud, Yeow-Liang Seah, Allen E. Yeoh, Hany Ariffin. Rapid Detection of Prognostically Important Childhood Acute Lymphoblastic Leukemia Chimeric Transcripts Using Multiplex SYBR Green Real-Time Reverse Transcription PCR. Ann Clin Lab Sci. 2008;38(4):338-43. 
7. Harrison CJ. Acute lymphoblastic leukemia. Clin Lab Med. 2011 Dec;31(4):631-647, ix. DOI: 10.1016/j. cll.2011.08.016

8. Brüggemann M, Schrauder A, Raff T, Pfeifer H, Dworzak M, Ottmann OG, et al. Standardized MRD quantification in European ALL trials: proceedings of the Second International Symposium on MRD assessment in Kiel, Germany, 18-20 September 2008. Leukemia. 2010 Mar;24(3):521-35. DOI: 10.1038/leu.2009.268

9. Ivanov IC, Jitaru D, Grigore GE, Zlei M, Ivanov A, Dumitraș $\mathrm{S}$, et al. Infant acute leukemia with lineage switch at relapse expressing a novel $\mathrm{t}(4 ; 11)(\mathrm{q} 21 ; \mathrm{q} 23)$ MLL-AF4 fusion transcript. Rev Romana Med Lab. 2013;21(1):47-58. DOI:10.2478/rrlm-2013-0017 DOI: 10.2478/rrlm-2013-0017

10. Boldeanu FM, Gruia AT, Ordodi VL, Serban M, Bader P, Kreyenberg H. Childhood Acute Lymphoblastic Leukemia: Detection of Minimal Residual Disease after Allogeneic Transplantation. Rev Romana Med Lab. 2012;20(3):245-53

11. Jardan D, Talmaci R, Jardan C, Coriu D, Colita A, Colita A, et al. Real-time qPCR for assessment of minimal residual disease in acute myeloid and lymphoid leukemia. Rev Romana Med Lab. 2011;19(4):349-57

12. van der Does-van den Berg A, Bartram CR, Basso G, Benoit YC, Biondi A, Debatin KM, et al. Minimal requirements for the diagnosis, classification, and evaluation of the treatment of childhood acute lymphoblastic leukemia (ALL) in the "BFM Family" Cooperative Group. Med Pediatr Oncol. 1992;20(6):497-505. DOI: 10.1002/mpo.2950200603

13. Gabert J, Beillard E, van der Velden VHJ, Bi W, Grimwade D, Pallisgaard N, et al. Standardization and quality control studies of "real-time" quantitative reverse transcriptase polymerase chain reaction of fusion gene transcripts for residual disease detection in leukemia A Europe Against Cancer Program. Leukemia. 2003 Dec;17(12):2318-57. DOI: 10.1038/sj.leu.2403135

14. R Core Team. R: A Language and Environment for Statistical Computing [Internet]. R Foundation for Statistical Computing; 2014. Available from: http:/www.R-project.org

15. Hunger SP, Lu X, Devidas M, Camitta BM, Gaynon PS, Winick NJ, et al. Improved survival for children and adolescents with acute lymphoblastic leukemia between 1990 and 2005: a report from the children's oncology group. J Clin Oncol Off J Am Soc Clin On- col. 2012 May 10;30(14):1663-9. DOI: 10.1200/ JCO.2011.37.8018

16. Bassan R, Hoelzer D. Modern therapy of acute lymphoblastic leukemia. J Clin Oncol Off J Am Soc Clin Oncol. 2011 Feb 10;29(5):532-43. DOI: 10.1200/ JCO.2010.30.1382

17. Siegel R, Naishadham D, Jemal A. Cancer statistics, 2012. CA Cancer J Clin. 2012 Feb;62(1):10-29. DOI: 10.3322/caac. 20138

18. Roganovic J. Acute Lymphoblastic Leukemia in Children. In: Guenova M, editor. Leukemia [Internet]. InTech; 2013 [cited 2017 Apr 19]. Available from: http:// www.intechopen.com/books/leukemia/acute-lymphoblastic-leukemia-in-children

19. Lustosa de Sousa DW, de Almeida Ferreira FV, Cavalcante Félix FH, de Oliveira Lopes MV. Acute lymphoblastic leukemia in children and adolescents: prognostic factors and analysis of survival. Rev Bras Hematol E Hemoter. 2015 Jul; 37(4):223-9. DOI: 10.1016/j.bjhh.2015.03.009

20. Pui C-H, Campana D, Pei D, Bowman WP, Sandlund JT, Kaste SC, et al. Treating childhood acute lymphoblastic leukemia without cranial irradiation. N Engl J Med. 2009 Jun 25; 360(26):2730-41. DOI: 10.1056/ NEJMoa0900386

21. Gökbuget N, Kneba M, Raff T, Trautmann H, Bartram C-R, Arnold R, et al. Adult patients with acute lymphoblastic leukemia and molecular failure display a poor prognosis and are candidates for stem cell transplantation and targeted therapies. Blood. 2012 Aug 30;120(9):1868-76.DOI: 10.1182/ blood-2011-09-377713

22. Liang D-C, Shih L-Y, Yang C-P, Hung I-J, Liu H-C, Jaing T-H, et al. Frequencies of ETV6-RUNX1 fusion and hyperdiploidy in pediatric acute lymphoblastic leukemia are lower in far east than west. Pediatr Blood Cancer. 2010 Sep;55(3):430-3. DOI: 10.1002/ pbc. 22628

23. Weltgesundheitsorganisation, Swerdlow SH, International Agency for Research on Cancer, editors. WHO classification of tumours of haematopoietic and lymphoid tissues: [... reflects the views of a working group that convened for an Editorial and Consensus Conference at the International Agency for Research on Cancer (IARC), Lyon, October 25 - 27, 2007]. 4. ed. Lyon: Internat. Agency for Research on Cancer; 2008. 439 p. (World Health Organization classification of tumours). 
24. Maurer J, Janssen JW, Thiel E, van Denderen J, Ludwig WD, Aydemir U, et al. Detection of chimeric BCR-ABL genes in acute lymphoblastic leukaemia by the polymerase chain reaction. Lancet Lond Engl. 1991 May 4;337(8749):1055-8. DOI: 10.1016/01406736(91)91706-Z

25. Sazawal S, Bhatia K, Gutierrez MI, Saxena R, Arya LS, Bhargava M. Paucity of TEL-AML 1 translocation, by multiplex RT-PCR, in B-lineage acute lymphoblastic leukemia (ALL) in Indian patients. Am J Hematol. 2004 May;76(1):80-2. DOI: 10.1002/ajh.20000

26. Oyekunle A, Haferlach T, Kröger N, Klyuchnikov E, Zander AR, Schnittger S, et al. Molecular Diagnostics, Targeted Therapy, and the Indication for Allogeneic Stem Cell Transplantation in Acute Lymphoblastic Leukemia. Adv Hematol. 2011;2011:1-8. DOI: $10.1155 / 2011 / 154745$

27. Diakos C, Xiao Y, Zheng S, Kager L, Dworzak M, Wiemels JL. Direct and indirect targets of the E2APBX1 leukemia-specific fusion protein. PloS One. 2014;9(2):e87602. DOI: 10.1371/journal.pone.0087602

28. Hu Y, He H, Lu J, Wang Y, Xiao P, Li J, et al. E2A$\mathrm{PBX} 1$ exhibited a promising prognosis in pediatric acute lymphoblastic leukemia treated with the CCLGALL2008 protocol. OncoTargets Ther. 2016 Nov;Volume 9:7219-25. DOI: 10.2147/OTT.S115257

29. Vey N, Thomas X, Picard C, Kovascovicz T, Charin C, Cayuela JM, et al. Allogeneic stem cell transplantation improves the outcome of adults with $\mathrm{t}(1 ; 19)$ /
E2A-PBX1 and $\mathrm{t}(4 ; 11) / \mathrm{MLL}-\mathrm{AF} 4$ positive B-cell acute lymphoblastic leukemia: results of the prospective multicenter LALA-94 study. Leukemia. 2006 Dec;20(12):2155-61. DOI: 10.1038/sj.leu.2404420

30. Ballerini P, Landman-Parker J, Cayuela JM, Asnafi V, Labopin M, Gandemer V, et al. Impact of genotype on survival of children with T-cell acute lymphoblastic leukemia treated according to the French protocol FRALLE-93: the effect of TLX3/HOX11L2 gene expression on outcome. Haematologica. 2008 Nov;93(11):165865. DOI: 10.3324/haematol.13291

31. Mansur MB, Emerenciano M, Brewer L, Sant'Ana M, Mendonça N, Thuler LCS, et al. SIL-TAL1 fusion gene negative impact in T-cell acute lymphoblastic leukemia outcome. Leuk Lymphoma. 2009 Aug;50(8):131825. DOI: $10.1080 / 10428190903040014$

32. D'Angio M, Valsecchi MG, Testi AM, Conter V, Nunes V, Parasole R, et al. Clinical features and outcome of SIL/TAL1-positive T-cell acute lymphoblastic leukemia in children and adolescents: a 10-year experience of the AIEOP group. Haematologica. 2015 Jan 1;100(1):e10-3.DOI: 10.3324/haematol.2014.112151

33. Matutes E, Pickl WF, van’t Veer M, Morilla R, Swansbury J, Strobl H et al. Mixed- phenotype acute leukemia: clinical and laboratory features and outcome in 100 patients defined according to the WHO 2008 classification. Blood. 2011;117:3163-71 DOI: 10.1182/ blood-2010-10-314682 